\begin{tabular}{|c|c|}
\hline \multicolumn{2}{|c|}{ PublisherInfo } \\
\hline PublisherName & BioMed Central \\
\hline PublisherLocation & London \\
\hline PublisherImprintName & BioMed Central \\
\hline
\end{tabular}

\title{
Nasal administration of an altered peptide of Hsp60 can treat adjuvant arthritis
}

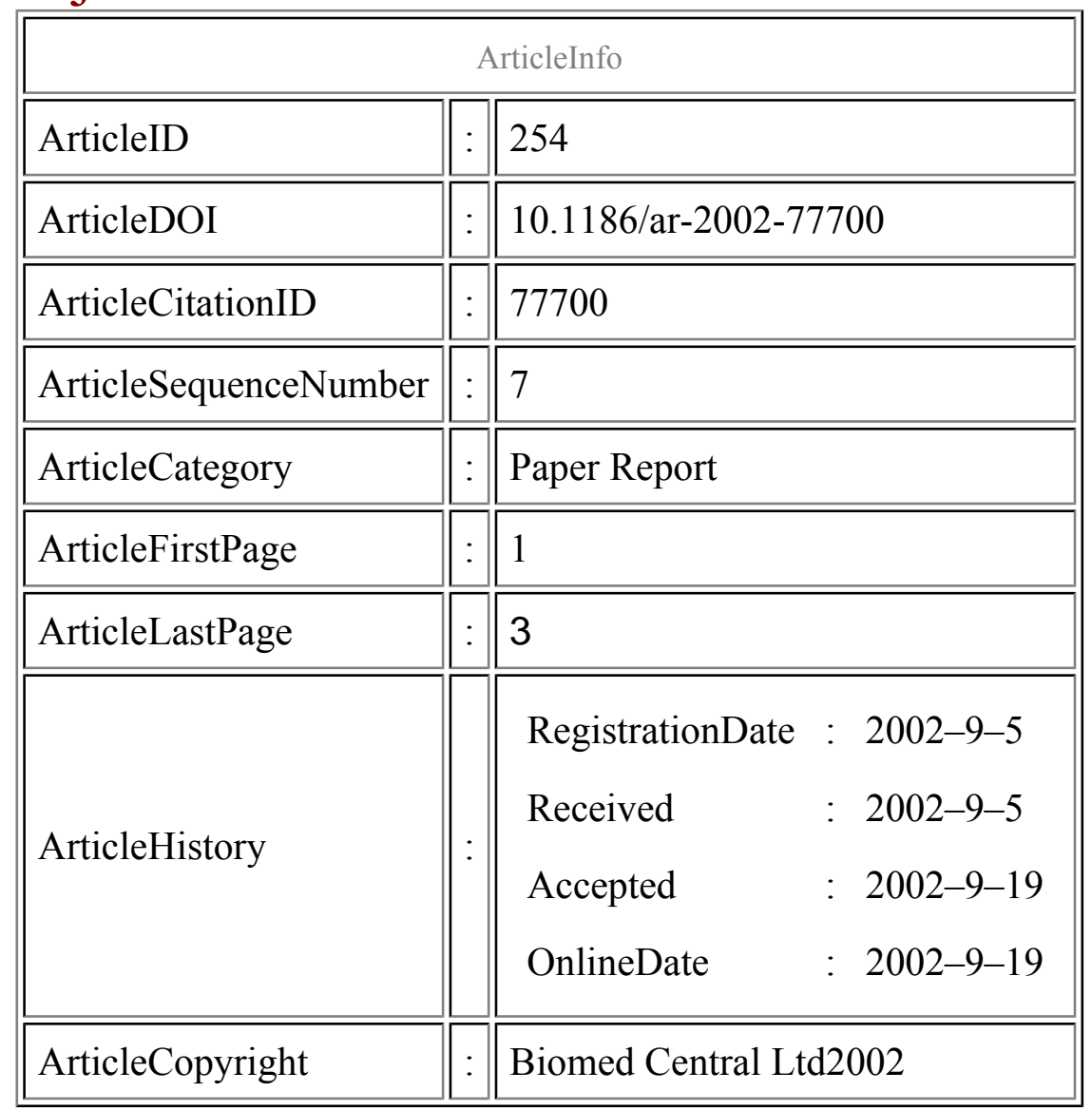




\begin{tabular}{|l|l|l||}
\hline ArticleGrants & $:$ & \\
\hline \hline ArticleContext & $:$ & 130754411 \\
\hline
\end{tabular}

Lucy Wedderburn, Affl

Aff1 Institute of Child Health, UCL, UK

\section{Keywords}

Adjuvant-induced, animal model, arthritis, IL-10, nasal tolerance, regulatory T cell.

\section{Context}

There is continued interest in mechanisms of tolerance induction in inflammatory arthritis. The induction of tolerance to peptides derived from heat shock proteins (Hsp), by oral or nasal administration, has been shown to be a method of partially suppressing arthritis in the rat adjuvant induced arthritis (AIA) model. In this study the authors used an altered peptide of the Hsp 60 molecule, 180-188183L-Ain which amino acid 183 has been mutated from leucine to alanine, to induce tolerance and to suppress arthritis. This peptide has a higher binding affinity for the rat class II major histocompatibility complex (MHC) molecule (RT1.B1) than the parent hsp180-188 peptide.

\section{Significant findings}

Administration of 180-188183L-A led to a profound reduction in incidence and severity of disease compared to controls, and could also reduce disease when given to animals who already had established arthritis. This protection could be transferred to naïve animals using concanavalin (Con-A) activated splenocytes from animals given 180-188183L-A. Mandibular lymph node cells specific for 180-188183LA after nasal tolerance induction produced interleukin (IL)-10 as well as IL-4 and transforming growth factor (TGF) $\beta$. The use of anti-IL-10 antibody could block suppression in vitro while anti-IL-4 and antiTGF $\beta$ did not alter the suppressive effect of lymph node cells on proliferation to hsp60.

\section{Comments}


The key observations coming out of this study are that an altered peptide ligand of the hsp60 molecule can suppress arthritis in the AIA model, not only by prior administration but also in established disease. It would appear that 'regulatory' cells are generated after administration of this peptide, which are present in local lymph nodes (but not distant ones such as inguinal nodes) and which produce IL-10 as well as IL-4 and TGF $\beta$. However the use of anti-IL-10 in vivo was not tested, meaning that the significance of the cytokine data to the mechanism of 'suppression' in vivo is not clear from the data presented. The authors summarize their conclusions by suggesting that IL-10 plays an important role in 'dominant tolerance' induced by the altered peptide when given by the nasal route. This work contributes to the body of evidence, which suggests that nasal or oral tolerance induction using peptides may be used to suppress autoimmune diseases including arthritis. The study is limited by the fact that the cytokine work is all from in vitro data and the conclusions from this need to be tested in vivo. Such studies may well suggest new avenues which could provide therapeutic agents for the induction of tolerance.

\section{Methods}

Adoptive transfer, animal model adjuvant induced arthritis, cytokine staining, ELISA, proliferation assay.

\section{References}

1. Prakken BJ, Roord S, van Kooten PJ, Wagenaar JP, van Eden W, Albani S, Wauben MH: Inhibition of adjuvant-induced arthritis by interleukin-10-driven regulatory cells induced via nasal administration of a peptide analog of an arthritis-related heat-shock protein $60 \mathrm{~T}$ cell epitope. Arthritis Rheum. 2002, 46(7): 1937-1946. 